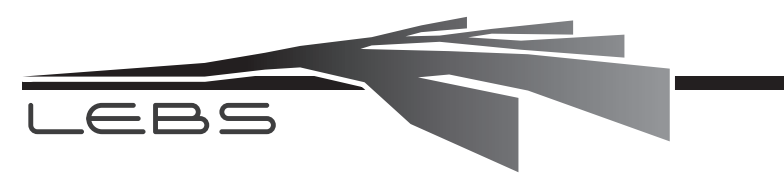

\section{Mate Preferences toward Agency and Communion}

\author{
Marcin Moroń \\ Department of Social and Environmental Psychology, University of Silesia, \\ Grażyńskiego 53 40-126 Katowice, Poland \\ "Author for correspondence (marcin.moron@us.edu.pl)
}

Agency and communion constitute two fundamental dimensions of social perception. Universal dimensions of mate preferences represent both agentic and communal content, but a direct test of mate preferences toward agency and communion is lacking. The present study examined preferences toward agentic and communal traits in mate preferences among 206 heterosexual individuals (112 females), analysing the role of the target's sex and actor's sexual strategy. Results showed that women demonstrated higher expectations toward agentic and communal traits in a potential partner than men. Preference for agency in short-term relationships did not differ from preferences toward agency and communion in long-term relationships, but preferences toward communion of partner in short-term relationships was significantly lower. These results were discussed in light of the signaling role of agency and communion in human mating behavior.

\section{Keywords}

mate preferences, agency, communion

\section{Introduction}

Two dimensions of content are basic in self and others' perception: agency and communion (Abele \& Wojciszke, 2014). Agency refers to goal-achievement and task functioning (competence, dominance) whereas communion refers to maintenance of relationships, social functioning and morality (Abele \& Wojciszke, 2007). Assessment of oneself and others on dimensions of agency and communion is automatic (Todorov, 2011) and have important emotional and behavioral consequences (Abele \& Wojciszke, 2014). The dual perspective model of agency and communion (Wojciszke, Baryla, Parzuchowski, Szymkow, \& Abele, 2011) posits that the dimension of agency is primary in self-perception. Wojciszke, Bazinska, and Jaworski (1998) demonstrated that in other's impression formation, communal descriptors are chronically accessible and are better predictors of valence of the overall impression. In the romantic relationship, communal traits are also more preferable than agentic (Abele \& Brack, 2013). Given the primacy of inferencing the communal and agentic content in image impression formation this should suggest that specific preferences toward these two dimensions of interpersonal characteristics are present also in mate selection.

An examination of the basic dimensions of mate preferences shows, evidently, that they reflect a communal and agentic content. Among ten of the most desired traits in the analysis conducted by Buss and Barnes (1986) there were six communal traits (e.g. honest, affectionate, kind, understanding) and three agentic traits (considerate, intelligent, dependable). Shackelford, Schmitt, and Buss (2005) proposed four universal dimensions of mate preferences: Love vs. Status/Resources; Dependable/Stable vs. Good Looks/Health; Education/Intelligence vs. Desire for Home/Children; and Sociability vs. Similar Religion, in which agentic and communal traits frequently constitute different ends of a specified mate dimension (e.g. love as a communal characteristic and status/resources as a agentic characteristic). Among 12 dimensions of mate preferences distinguished recently by Schwarz and Hassebrauck (2012), eight traits were communal (e.g. kind and understanding, pleasant, generous, sociable, domestic), whereas three had agentic content (intellectual, wealthy, dominant).

Although previous research demonstrated that universal dimensions of mate preferences and the most desirable characteristic of a potential partner are both agentic and communal in nature, research that directly addresses the mating preferences toward agency and communion is lacking. In the present study an attempt to examine preferences toward agency and communion was made. The predominance of the communal traits in dimensions of mate preferences was a reason to predict that the preference toward communion in a potential partner will be higher than toward agency (hypothesis 1). This prediction is also based on theses from the dualpersective model of agency and communion that posits that communal content is primary among the fundamental dimensions in others' perception (Abele \& Wojciszke, 2014).

Based on parental investment theory (Trivers, 1972) it was hypothesized that women will prefer both agency and communion in a potential partner more than men (hypothesis 2). Given the higher minimal parental investment in women compared to men, female preferences for both agency and communion in a potential partner should be increased to optimize the genetic heritage for potential offspring by selecting a male with valued traits for both resource gaining and developing social relationships (Buss, 1989; Buss et al., 1990; Buss \& Schmitt, 1993).

According to Sexual Strategies Theory (Buss \& Schmitt, 1993) it was predicted that in short-term relationships women will prefer agency and communion as highly as in long-term relationships, whereas men will have preference toward agency and communion in longterm relationships of a level similar to women, but lower preference for both traits in short-term relationships (hypothesis 3). Agentic traits of a potential partner in 
long-term relationships may provide an individual (both women and men) with better socioeconomic perspectives, while communal traits could predict a desirable level of intimacy as well as caregiving abilities and parental investment in children. In a short-term relationship high female preferences for both agency and communion could be a result of a tendency to gain access to external resources provided by males which may equip them and their children. In short-term relationships men would be expected to have less stringent requirements toward agency and communion of a female partner aiming to gain access to wider range of female sexual partners (Kenrick, Sadalla, Groth, \& Trost, 1990).

\section{Method}

Participants

The participants were 206 individuals (112 female) ranging in age from 18 to 30 years old, $M=23.07 ; S D=2.49$. All individuals were of Polish ethnicity and of the same cultural background. The participants were students from various university and polytechnical courses, and did not receive any payment for participation in the study.

\section{Measure}

Scales measuring Agency and Communion (Wojciszke \& Szlendak, 2010). The scales consist of 30 items that were adjectives with confirmed clear agentic or communal content and with balanced trait's desirability: 15 adjectives measure agency (e.g. active, determined, self-confident) and 15 adjectives measure community (e.g. supportive, sensitive toward others, compassionate). Participants assessed each adjective on a Likert-type scale from 1 (definitely not important) to 7 (definitely very important) indicating the preference for trait in a potential partner. A result of each scale was computed as an average of participants' responses to items of the scale. In every experimental condition reliabilities of scales measuring agency, $.81 \leq \alpha s \leq .89$, and communion, $.86 \leq \alpha s \leq .94$, were satisfactory.

\section{Experimental design}

In the short-term relationship condition participants (54 females and 49 males) were asked to indicate "how important is it for your partner in a short-term romantic relationship with no commitments to possess each of the traits demonstrated in the following list of 30 characteristics". In the long-term relationship condition participants (58 females and 45 males) were asked to indicate "how important is it for your partner in a longterm, serious romantic relationship with the possibility to become a husband/wife to possess each of the traits demonstrated in the following list of 30 characteristics". The participants filled the paper-and-pencil survey including basic demographics and Scales measuring Agency and Communion in one of the experimental versions.

\section{Results}

The 2 (sex; between-participants) x 2 (short-term vs. longterm sexual strategy; between-participants) x 2 (trait content: agency vs. communion; within-participants)
ANOVA was conducted. The main effect of sex, $F(1,202)$ $=7.93 ; p<.006 ; \eta_{p}^{2}=.04$, and sexual strategy, $F(1,202)$ $=27.43 ; p<.001 ; \eta_{p}^{2}=.12$, were significant. Women tend to have higher expectations toward the level of both traits in potential partners, $M=5.29 ; S D=.80$, than men, $M=$ 4.96; $S D=.82$; Cohen's $d=.40$. Preferences in long-term relationships were also higher, $M=5.42 ; S D=.64$, than for short-term relationships, $M=4.85 ; S D=.87, t(204)=5.28$; $p<.001$; Rosnow - Rosenthal's $d=.75$. The main effect of trait content was also significant, $F(1,202)=10.27 ; p<$ $.001 ; \eta_{p}^{2}=.05$, and was qualified by interaction with sexual strategy, $F(1,202)=22.08 ; p<.001 ; \eta_{p}^{2}=.10$. Agency was more preferred, $M=5.26, S D=.82$, than communion, $M$ $=5,02, S D=1.14, t(205)=3.05 ; p<.003$; Cohen's $d=.21$. The post-hoc Scheffe's test showed that preferences toward agency, $M=5.37 ; S D=.71$ and communion, $M=5.48 ; S D$ $=.82 \mathrm{in} \mathrm{long-term} \mathrm{relationships} \mathrm{did} \mathrm{not} \mathrm{differ} \mathrm{significantly}$ from each other, and did not differ from preferences toward agency in short-term relationships, $M=5.15 ; S D=.92$. Preferences toward communion in short-term relationships were significantly lower than other preferences, $M=4.56$; $S D=1.23$. Interactional effects of sex and trait content was insignificant, $F(1,202)=.03 ; p<.87 ; \eta_{p}{ }^{2}<.001$, just like the three way interaction of sex, sexual strategy and trait content, $F(1,202)=.61 ; p<.44 ; \eta_{p}^{2}<.003$. The results are demonstrated in Figure 1.

\section{Discussion}

The obtained results showed that higher mating preferences refers to the agency, rather than to the communion of a potential partner, which was contrary to predictions. Figueredo, Sefcek, and Jones (2006) demonstrated that evaluation of ideal partner personality is strongly correlated with self-rated personality. If self-perception is dominated by agency (Wojciszke et al., 2011), more importance could also be given to agentic traits of a future partner. Furthermore, such aspects of agency like vigorous, convincing, and go-ahead could provide an individual with a more exposed social position which is connected with popularity, and better access to sexual opportunities (Choukas-Bradley, Giletta, Widman, Cohen, \& Prinstein, 2014). It is important to note that the effect of giving higher importance to agency depends on the sexual strategy. Agency and communion were equally important in longterm relationships, but communion was less important in short-term relationships. Lower preference toward communion in short-term relationships may be a result of the morality aspect of communion (Wojciszke, Bazinska, \&

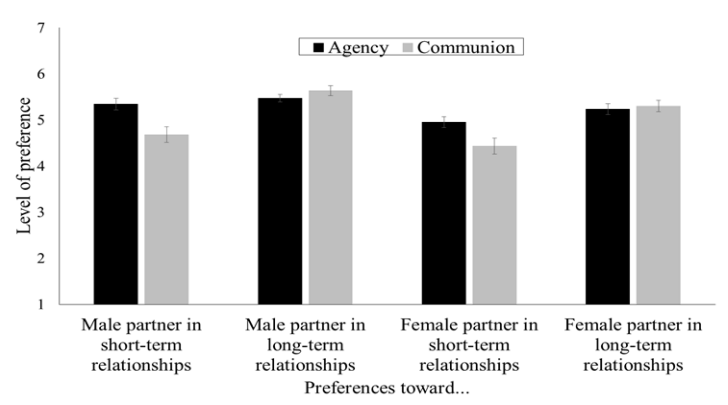

Figure 1. The mean level of preferences toward agency and communion by sexual strategy and sex. Error bars indicate standard errors. 
Jaworski, 1998), which could be especially undesirable due to producing doubts connected with engagement in random sexual activity.

Women showed higher preferences toward both agency and communion in potential partners than men. This pattern was not qualified by the interaction with content of traits or with sexual strategy. Women are interested in better overall qualities of potential male partners regardless of the type of relationship which is ultimately caused by their increased parental investment (Trivers, 1972).

In long-term relationships both men and women demonstrated high preferences for agency and communion in potential partners. These results indicate that for serious and long lasting relationships as good as possible partners are selected. High preferences toward agency and lower toward communion in short-term relationships were analogous for men and women, which is somewhat contrary to the hypotheses that were taken from sexual strategy theory (Buss \& Schmitt, 1993). The high expectation for agentic traits of a potential male partner exerted by women may be a result of searching for signals of resource possession or ability to gain resources, which may meet two main goals of women engaged in short-term relationship: immediate resource extraction and assessing prospecting long-term mates (Buss \& Schmitt, 1993). However, lower expectations toward male partner's communion in short-term relationships may indicate that females are more interested rather in immediate resource extraction, than in evaluating qualities like parental skills and understanding in male short-term partner. Men could treat the agentic traits of women as indicators of their openness to casual sexual contact (Campbell, Cronk, Simpson, Milroy, Wilson, \& Dunham, 2009). Low male preference for communal traits in female short-term partners may result from a general lower expectations toward personal qualities of female in short-term relationships or from a expected lower sexual accessibility of highly moral and communal individuals (Walsch, 1993). In the present study the sexual strategy adopted by participants in their life course was not controlled, so that it was impossible to partial out the effects of individual differences in the drive for short- or long-term relationships on preferences toward agency and communion. In future research the actual preference for short and long-term partners (e.g. sociosexual orientation) should be examined as a covariate in analysis of preference toward agency and communion.

\section{Acknowledgements}

The author would like to thank Paulina Janiszewska, and Agnieszka Gliwa, Anna Gunia, Martyna Pieróg, Paulina Pycior, Joanna Grzegorzewska, and Patrycja Dziuba for their help in collecting data.

\section{References}

Abele, A. E., \& Brack, S. (2013). Preference for other persons' traits is dependent on the kind of social relationship. Social Psychology, 44, 84-94. doi: 10.1027/1864 9335/a000138)

Abele, A. E., \& Wojciszke, B. (2007). Agency and communion from the perspective of self versus others. Journal of Personality and Social Psychology, 93, 751763. doi: 10.1037/0022-3514.93.5.751

Moroń LEBS Vol. 6 No.1 (2015) 1-4
Abele, A. E. \& Wojciszke, B. (2014). Communal and agentic content in social cognition: A dual perspective model. Advances in Experimental Social Psychology, 50, 195-255. doi: 10.1016/B978-0-12-800284-1.00004可)

Buss, D. M. (1989). Sex differences in human mate preferences: Evolutionary hypotheses tested in 37 cultures. Behavioral and Brain Sciences, 12, 1-49. doi: 10.1017 S0140525X00023992)

Buss, D. M., Abbott, M., Angleitner, A., Asherian, A., Biaggio, A., Blanco-Villasenor, A., ... Yang, K. S. (1990). International preferences in selecting mates: A study of 37 cultures. Journal of Cross Cultural Psychology, 21, 5-47. doi: 10.1177/0022022190211001)

Buss, D. M, \& Barnes, M. (1986). Preferences in human mate selection. Journal of Personality and Social Psychology, 50, 559-570. doi: 10.1037/0022-3514.50.3.559)

Buss, D. M., \& Schmitt, D. P. (1993). Sexual strategies theory: An evolutionary perspective on human mating. Psychological Review, 100, 204-232. doi: 10.1037/0033-295X.100.2.204

Campbell, L., Cronk, L., Simpson, J. A., Milroy, A., Wilson, C. L., \& Dunham, B. (2009). The association between men's ratings of women as desirable longterm mates and individual differences in women's sexual attitudes and behaviors. Personality and Individual Differences, 46, 509-513. doi: 10.1016 i.paid.2008.12.001)

Choukas-Bradley, S., Giletta, M., Widman, L., Cohen, G. L., \& Prinstein, M. J. (2014). Experimentally measured susceptibility to peer influence and adolescent sexual behavior trajectories: A preliminary study. Developmental Psychology, 50, 2221-2227. doi: 10.1037 a0037300

Figueredo, A. J., Sefcek, J. A., \& Jones, D. N. (2006). The ideal romantic partner personality. Personality and Individual Differences, 41, 431-441. doi: 10.1016 i.paid.2006.02.004

Kenrick, D. T., Sadalla, E. K., Groth, G., \& Trost, M. R. (1990). Evolution, traits, and the stages of human courtship: Qualifying the parental investment model. Journal of Personality, 58, 97-116. doi: 10.1111/i.14676494.1990.tb00909.X)

Schwarz, S., \& Hassebrauck, M. (2012). Sex and age differences in mate-selection preferences. Human Nature, 23, 447-466. doi: 10.1007/s12110-012-9152-x)

Shackelford, T. D., Schmitt, D. P., \& Buss, D. M. (2005). Universal dimensions of human mate preferences. Personality and Individual Differences, 39, 447-458. doi: 10.1016/i.paid.2005.01.023)

Todorov, A. (2011). Evaluating faces on social dimensions. In A. Todorov, S. T. Fiske, and D. Prentice (Eds.), Social neuroscience: Toward understanding the underpinnings of the social mind (pp. 54-76). New York: Oxford University Press.

Trivers, R. (1972). Parental investment and sexual selection. In B. Campbell (Ed.), Sexual selection and the descent of man (pp. 136-179). Chicago: Aldine-Atherton.

Walsch, A. (1993). Love styles, masculinity/femininity, physical attractiveness, and sexual behavior: A test of evolutionary theory. Ethology and Sociobiology, 14, 25-38. doi: 10.1016/0162-3095(93)90015-A

Wojciszke, B., Baryla, W., Parzuchowski, M., Szymkow, A., \& Abele, A., E. (2011). Self-esteem is dominated by agentic over communal information. European Journal of Social Psychology, 41, 617-627. doi: 
10.1002/ejsp.791)

Wojciszke, B., Bazinska, R., \& Jaworski, M. (1998). On the dominance of moral categories in impression formation. Personality and Social Psychology Bulletin, 24, 1251-1263. doi: 10.1177/01461672982412001)

Wojciszke, B., \& Szlendak, M. (2010). Skale do pomiaru orientacji sprawczej i wspólnotowej [Scales measuring agency and communion]. Psychologia Społeczna, 5, 57-70. 